\title{
EXPOSIÇÃO HUMANA A SUBSTÂNCIAS QUÍMICAS POTENCIALMENTE TÓXICAS NA DIETA E OS RISCOS PARA SAÚDE
}

\author{
Andréia Nunes Oliveira Jardim e Eloisa Dutra Caldas* \\ Curso de Ciências Farmacêuticas, Universidade de Brasília, Campus Universitário Darcy Ribeiro, 70910-900 Brasília - DF, Brasil \\ Recebido em 16/9/08; aceito em 11/2/09; publicado na web em 23/7/09
}

\begin{abstract}
CHEMICAL DIETARY EXPOSURE AND THE RISKS TO HUMAN HEALTH. Humans are exposed to a variety of chemicals from the consumption of food, including undesirable compounds such as pesticides and mycotoxins. Chemical human risk assessment is a process intended to estimate the risk to a given population from the exposure to a chemical (or to a chemical group having the same mechanism of action). The process consists of four steps, namely hazard identification, hazard characterization, exposure assessment and risk characterization. Chemical dietary risk assessment is an essential procedure to establish safe food standards. In this review the tools and data sources currently used in the risk assessment process will be discussed.
\end{abstract}

Keywords: food; chemical exposure; dietary risk assessment.

\section{INTRODUÇÃO}

Nos alimentos que consumimos está presente uma grande variedade de substâncias químicas, como aquelas essenciais para a manutenção da saúde, como vitaminas, minerais e proteínas, e algumas potencialmente tóxicas, como micotoxinas, resíduos de pesticidas, aditivos e metais pesados. A falta de algum nutriente ou a presença excessiva no alimento de substâncias tóxicas pode significar um risco à saúde humana.

A preocupação com a presença de substâncias químicas nos alimentos iniciou-se na década de 1940 nos Estados Unidos. Em 1954, Lehman e Fitzhugh, dois toxicologistas da FDA (Food and Drug Administration), definiram as bases para o que hoje é chamado de IDA (Ingestão Diária Aceitável). ${ }^{1}$ Posteriormente, o Conselho Nacional de Pesquisa americano elaborou o relatório Avaliação do Risco do Governo Federal: Gerenciando o Processo, onde foram estabelecidas as bases dos processos de avaliação e de gerenciamento do risco. ${ }^{2}$

A avaliação do risco objetiva estimar o risco a um dado organismo alvo, sistema ou (sub)população, incluindo a identificação das incertezas esperadas, após a exposição a um agente particular, levando em consideração as características inerentes ao agente e as do sistema alvo. ${ }^{3}$ Avaliar o risco causado pela exposição humana a substâncias químicas na dieta é amplamente reconhecido como um processo fundamental no desenvolvimento de padrões alimentares seguros. ${ }^{4} \mathrm{~A}$ avaliação é conduzida, por exemplo, pelos governos durante o processo de registro de aditivos alimentares ou de substâncias que serão utilizadas no manejo agropecuário, como pesticidas e drogas veterinárias. No caso de contaminantes presentes nos alimentos, os estudos subsidiam ações gerenciais que levem ao controle da contaminação e diminuição da exposição humana.

No Brasil, a Agência Nacional de Vigilância Sanitária (ANVISA) é responsável pelo processo de registro de aditivos, pesticidas e drogas veterinárias e pela condução de avaliação do risco da exposição humana a estas substâncias e a contaminantes em alimentos. ${ }^{5}$ Internacionalmente, procedimentos de avaliação do risco são conduzidos pelos comitês científicos da Organização Mundial de Saúde (OMS) e Organização para Alimentação e Agricultura (Food and Agriculture Organization - FAO) para subsidiar o estabelecimento de padrões alimentares pelo Codex Alimentarius. ${ }^{6} \mathrm{O}$ JECFA (Joint FAO/WHO

*e-mail: eloisa@unb.br
Expert Committee on Food Additives) avalia questões relativas a aditivos alimentares, contaminantes e drogas veterinárias e o JMPR (Joint FAO/WHO Meeting on Pesticide Residues) aquelas relacionadas a resíduos de pesticidas.

Enquanto a avaliação do risco é um processo de base científica, o gerenciamento do risco envolve tomada de decisões pelas agências reguladoras que levam em consideração, além de informações técnicas relevantes relacionadas ao dano à saúde e ao risco, fatores políticos, sociais e econômicos. A troca de informações sobre o risco entre avaliadores, gerenciadores, mídia, grupos de interesse e público em geral se dá no âmbito da comunicação de risco. ${ }^{3} \mathrm{~A}$ avaliação, o gerenciamento e a comunicação do risco são processos que interagem entre si, sendo partes de um processo maior, a análise do risco (Figura 1)

Neste trabalho, as etapas do processo de avaliação do risco da exposição humana a substâncias químicas na dieta serão apresentadas e discutidas à luz dos conhecimentos atuais. O foco desta revisão são as substâncias potencialmente tóxicas ao homem, entretanto, os princípios da avaliação do risco podem ser igualmente aplicados à deficiência de nutrientes na dieta.

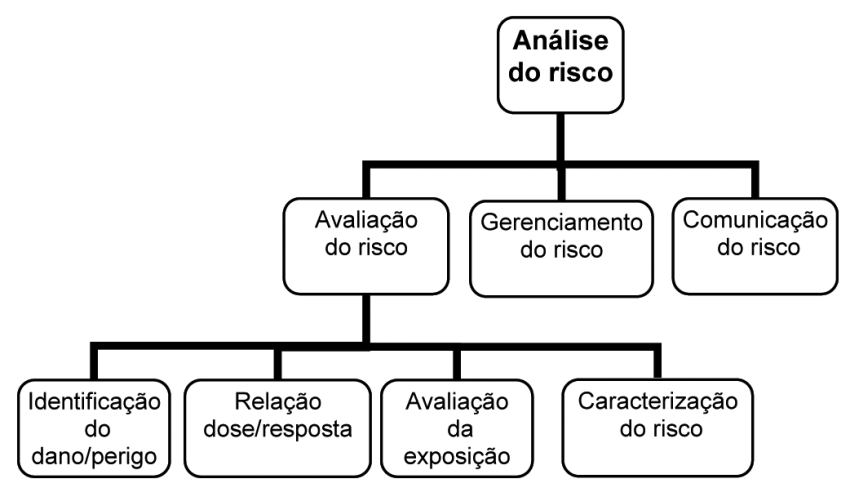

Figura 1. Etapas da análise e avaliação do risco

\section{AVALIAÇÃO DO RISCO NA DIETA}

Risco pode ser definido como a probabilidade de um efeito adverso ocorrer em um organismo, sistema ou (sub)população cau- 
sado sob condições específicas pela exposição a um agente. ${ }^{4} \mathrm{O}$ risco dependerá do grau de toxicidade da substância e da quantidade à qual a população foi exposta. O risco é então função da toxicidade e da exposição (Equação 1).

Risco $=\mathrm{f}($ toxicidade, exposição $)$

A exposição a substâncias químicas na dieta pode ser crônica ou aguda. A exposição crônica é caracterizada pela ingestão de pequenas quantidades da substância durante um longo período, e a exposição aguda pela ingestão de quantidades grandes durante um intervalo de até 24 h. Enquanto algumas substâncias apresentam maior risco de exposição crônica, como aquelas potencialmente carcinogênicas, outras podem oferecer risco durante uma exposição aguda, como algumas neurotóxicas.

Dentre as substâncias que podem estar presentes nos alimentos e apresentar um potencial risco à saúde humana estão as advindas do processamento e estocagem dos alimentos, como acrilamida e nitrosaminas, toxinas de fungos (micotoxinas), de bactérias e de outros organismos, metais pesados presentes naturalmente no ambiente e compostos orgânicos ou inorgânicos advindos da atividade industrial e/ou doméstica, como metais pesados e dioxinas. Resíduos de pesticidas e de drogas veterinárias podem ser encontrados nos alimentos após o manejo agrícola e/ou pecuário com estas substâncias, visando o controle de pragas e doenças. Aditivos são adicionados nos alimentos com objetivos tecnológicos definidos, como manter as características químicas, físicas e biológicas dos alimentos processados ou imprimir outras, como sabor, cor ou textura. A estrutura química de algumas dessas substâncias e a fonte de exposição humana estão mostradas na Tabela 1.

O processo de avaliação do risco envolve 4 etapas, ilustradas também na Figura 1: identificação do dano (ou perigo), caracterização do dano/relação dose-resposta, avaliação da exposição e caracterização do risco.

\section{Identificação do dano (perigo)}

A identificação do dano, primeira etapa do processo de avaliação do risco, tem como objetivo identificar os potenciais efeitos adversos à saúde humana associados à exposição a uma dada sustância química. ${ }^{7,8}$ Nesse processo, podem ser utilizadas diferentes fontes de informações, incluindo a relação estrutura molecular e atividade (Structure-Activity Relationship - SAR), testes in vitro, estudos com animais de laboratório e estudos com seres humanos.

Informações obtidas da SAR podem ser utilizadas numa situação emergencial, quando não há dados toxicológicos adequados disponíveis para a substância, ou quando o nível de exposição humana é muito baixo. A SAR é baseada na premissa de que a atividade biológica da substância é relacionada à sua estrutura química e à presença de grupos funcionais específicos, sendo extremamente útil para predizer sua atividade baseada em dados disponíveis para compostos relacionados estruturalmente. ${ }^{9} \mathrm{O}$ resultado pode indicar o potencial dano da substância no organismo, suas propriedades toxicocinéticas e a necessidade da realização de testes experimentais..$^{10} \mathrm{O}$ estabelecimento de padrões de segurança baseado em SAR assume que a exposição humana é suficientemente menor que as doses tóxicas de substâncias estruturalmente análogas para as quais dados de toxicidade estão disponíveis. Essa estratégia foi utilizada pelo FDA para propor que uma concentração de $0,5 \mu \mathrm{g} / \mathrm{kg}$ ou $\mu \mathrm{g} / \mathrm{L}$ poderia ser usada como um valor de regulação na avaliação de substâncias que migram de embalagens para o alimento. $\mathrm{O}$ JECFA refinou essa estratégia na avaliação de flavorizantes utilizados como aditivos em alimentos, ${ }^{11}$ baseando-se no diagrama de decisão publicado por Cramer et al.. ${ }^{12}$ Esse diagrama divide as substâncias em três diferentes classes toxicológicas, de acordo com estrutura química e grupos funcionais presentes. Os níveis seguros de exposição em cada classe foram derivados a partir de valores de NOAEL (No-ObservedAdverse-Effect-Level) estabelecidos para várias substâncias testadas em animais. Algumas limitações têm sido identificadas na classificação de Cramer, ${ }^{13,14}$ indicando a necessidade de se reavaliar esta estratégia, com base em dados toxicológicos mais recentes. O FDA tem desenvolvido ferramentas computacionais empregando modelos quantitativos de SAR (Quantitative Structure-Activity Relationship - QSAR) para indicadores de toxicidade (endpoints) sensíveis como carcinogenicidade, mutagenicidade e toxicidade reprodutiva. ${ }^{15}$ SAR é extremamente útil para identificar substâncias ou seus metabólitos que possam iniciar o processo da carcinogênese por meio da interação covalente entre um sítio eletrofílico da molécula com o DNA. ${ }^{16}$

Testes in vitro são utilizados, principalmente, com o propósito de triagem e para classificar as substâncias presentes nos alimentos de acordo com sua toxicidade. As novas estratégias em toxicologia in vitro têm focado no desenvolvimento de marcadores moleculares para detectar efeitos adversos em níveis de exposição mais baixos que aqueles que causariam uma resposta patológica clinicamente observável. Novas ferramentas para acessar a resposta celular incluem o uso de tecnologias genômicas (sequência do DNA), proteómica (proteínas expressadas pelo genoma) e bioinformática. ${ }^{17}$ Apesar de estudos in vitro não poderem acessar a complexidade fisiológica de um organismo vivo, eles são, e serão cada vez mais no futuro, essenciais e necessários para auxiliar na compreensão do mecanismo de ação tóxica de substâncias químicas e na etiologia das doenças.

Estudos com animais de laboratório são atualmente as principais fontes de informação para identificar e caracterizar o dano ao homem de substâncias químicas presentes em alimentos. Os estudos conduzidos hoje têm sua origem nos anos 1940 e foram posteriormente refinados com o uso de animais geneticamente padronizados e a inclusão de outros endpoints, ao mesmo tempo em que conceitos éticos relacionados ao uso de animais foram sendo discutidos. A partir da década de 1980 houve a introdução de protocolos harmonizados, como os da OECD (Organization for Economic Co-operation and Development), para promover a aceitabilidade internacional dos estudos. ${ }^{18}$ Esses protocolos são periodicamente reavaliados com o intuito de diminuir o número de animais envolvidos e garantir seu bem estar, ao mesmo tempo em que fornecem o maior número de informação possível sobre o composto. ${ }^{19}$ Entre as questões emergentes relacionadas aos estudos com animais identificadas por Barlow et al. ${ }^{20}$ estão o uso de novas tecnologias, como a genômica e a proteómica, o uso de animais transgênicos, principalmente para testes de carcinogenicidade de curta duração, e a importância de endpoints atualmente não totalmente acessados, como efeitos neuropsicológicos, a resposta imunológica e alterações endócrinas. Antes de iniciar os testes toxicológicos com animais, porém, é importante fazer o máximo uso dos conhecimentos existentes sobre a natureza química da substância, bem como da indicação do mecanismo de ação e toxicocinética obtidas de estudos SAR e de testes in vitro.

O uso de dados de estudos em humanos para a identificação do dano tem um valor importante já que reduz a incerteza relacionada aos achados em ensaios com animais. Esses dados são principalmente derivados de estudos com desenho experimental ou epidemiológico observacional (caso controle ou cohorte). Estudos com desenho experimental têm a vantagem de controlar melhor os fatores de confundimento, presentes em estudos epidemiológicos, mas por questões éticas, financeiras e práticas, têm sido pouco utilizados. ${ }^{21}$ Uma exceção tem sido os estudos de inibição de acetilcolinesterase utilizados na avaliação de inseticidas organofosforados e carbamatos. ${ }^{22}$ Entre as ferramentas disponíveis para serem utilizadas em estudos epidemiológicos está o uso de indicadores biológicos representativos da exposição à substância de interesse. 
Tabela 1. Substâncias presentes nos alimentos com potencial risco à saúde humana

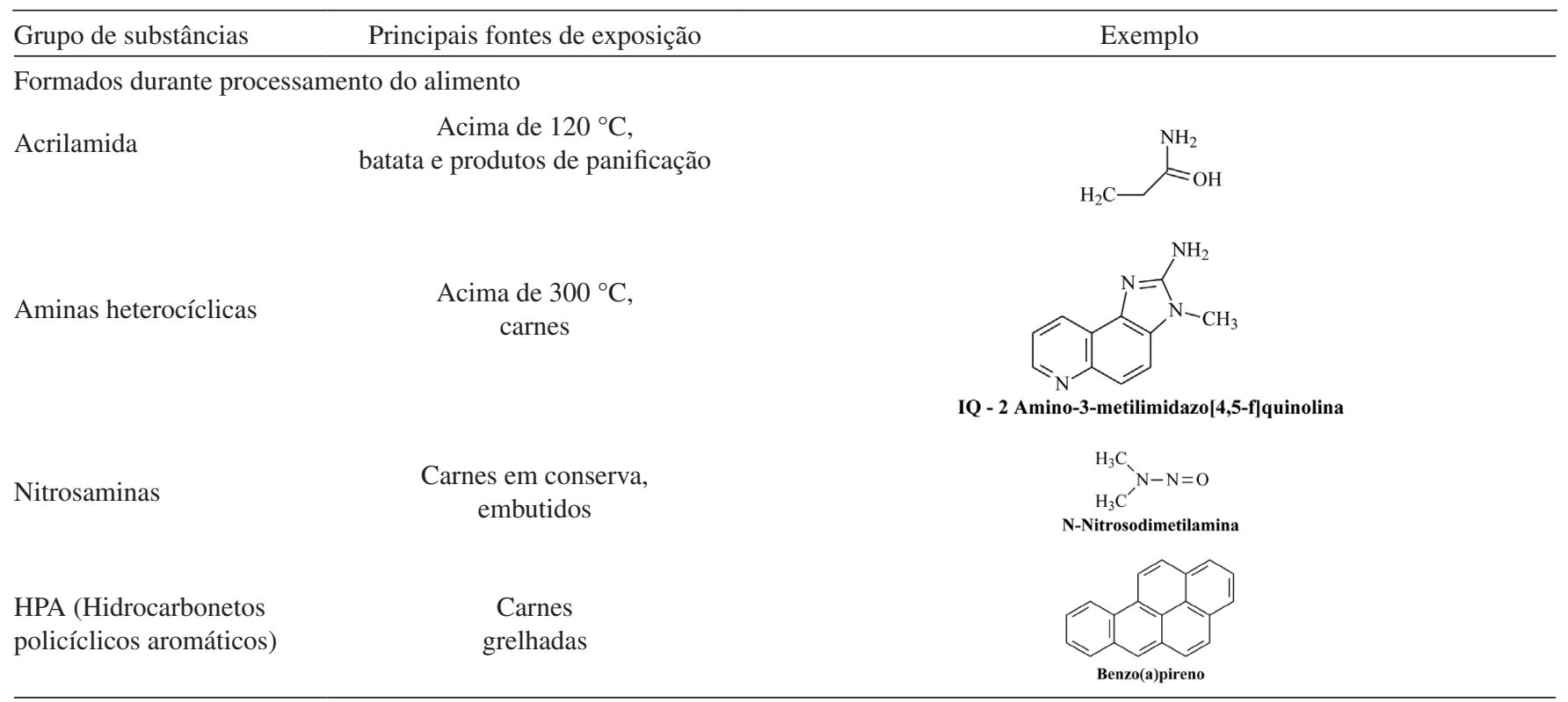

Componente de embalagens de alimentos

Ftalatos Embalagens $\begin{gathered}\text { plásticas } \\ \text { Ftalato de di(2-etil-hexila) }\end{gathered}$

Contaminantes ambientais

Metais pesados

Água, peixe

$\mathrm{CH}_{3} \mathrm{HgCl}$

Metilmercúrio

PCBs (Bifenilas

policloradas)

\section{Carnes,}

derivados de leite,

peixes e ovos
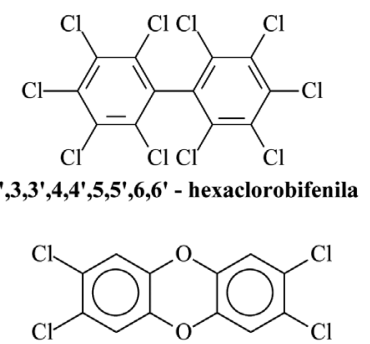

$\mathbf{2 , 3 , 7 , 8}$ - tetraclorodibenzo $[1,4]$ dioxina<smiles>Clc1cc(Cl)c2oc3c(Cl)cccc3c2c1</smiles>

Dibenzo-furanos policlorados

Sustâncias utilizadas no manejo agro-pecuário

Resíduos de pesticidas

Frutas,

verduras,

cereais

$$
\begin{gathered}
\mathrm{S} \\
\text { II } \\
\left(\mathrm{CH}_{3} \mathrm{O}\right)_{2} \mathrm{PSCHCH}_{2} \mathrm{CO}_{2} \mathrm{CH}_{2} \mathrm{CH}_{3} \\
\mathrm{CO}_{2} \mathrm{CH}_{2} \mathrm{CH}_{3} \\
\text { Malationa }
\end{gathered}
$$
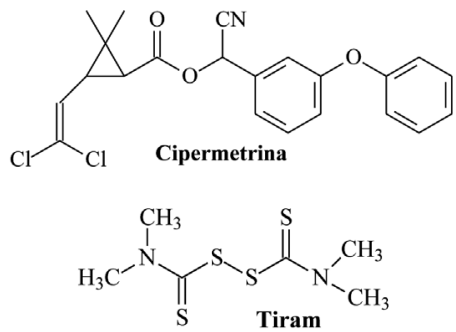
Tabela 1. continuação

\begin{tabular}{lcl}
\hline Grupo de substâncias & Principais fontes de exposição & Exemplo \\
\hline $\begin{array}{l}\text { Resíduos de drogas } \\
\text { veterinárias }\end{array}$ & $\begin{array}{l}\text { Carne, leite } \\
\text { e derivados }\end{array}$
\end{tabular}

Aditivos

Edulcorante

Alimentos dietéticos

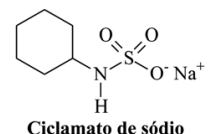

Conservante

Bebidas, sucos, iogurte

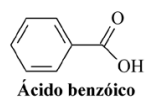

Micotoxinas

Aflatoxinas $\begin{gathered}\text { Cereais, amendoins, } \\ \text { castanhas }\end{gathered}$

Substâncias naturalmente presentes

Glicosídeos cianogênicos Mandioca brava

Linamarina

\section{Caracterização da relação dose/resposta}

Após a etapa de identificação do dano, a relação quantitativa entre a exposição e a incidência de resposta de um efeito adverso é avaliada. Estudos com animais de laboratório são as principais fontes de informação na caracterização da dose-resposta de substâncias potencialmente tóxicas presentes nos alimentos. Nesse processo, e consequentemente na posterior caracterização do risco, são adotadas estratégias diferentes quando os efeitos adversos possuem limiar de dose ou não (threshold ou no-treshold effects).

\section{Substâncias com limiar de dose para efeito adverso}

Para essas substâncias, nenhuma resposta biológica será evidente abaixo de uma dose específica. ${ }^{8}$ Nessa etapa, são estimadas as doses que não causou um efeito adverso nos animais testados (NOAEL) e/ou a menor dose na qual o efeito adverso foi observado (Lowest-Observed-Adverse-Effect-Level - LOAEL). O NOAEL pode ser definido como o nível de exposição no qual não existe aumento significativo na frequência ou severidade do efeito adverso entre a população exposta e a população controle. O NOAEL e o LOAEL, obtidos dos estudos mais críticos conduzidos na espécie mais sensível testada, são utilizados no cálculo dos parâmetros seguros de ingestão crônica e aguda no homem. Esses parâmetros, expressos em mg/kg de peso corpóreo, são calculados dividindo-se o NOAEL ou o LOAEL por um fator de incerteza, ou de segurança, para se extrapolar os resultados obtidos com animais de laboratório para a espécie humana. ${ }^{8,23,24}$

O fator de segurança 100, proposto em 1945 e adotado no segundo encontro do JECFA em 1957, é o valor normalmente utilizado no estabelecimento da ingestão segura de resíduos de pesticidas e drogas veterinárias, aditivos e contaminantes em alimentos. Esse valor assume que o ser humano pode ser até 10 vezes mais sensível ao agente que a espécie testada, e que alguns indivíduos da população humana podem ser até 10 vezes mais sensíveis que a média da população (Figura 2). Fatores de segurança maiores ou menores que 100 podem ser considerados em cada caso pelo comitê científico que avalia os estudos toxicológicos. Esse fator pode ser maior que 100 quando os estudos são incompletos ou inadequados, quando se quer acrescentar um fator adicional de proteção a um grupo altamente sensível da população, como crianças ou indivíduos com alguma patologia, ou na ausência de NOAEL; pode ser menor quando dados de toxicocinética e toxicodinâmica demonstram que o homem possa ser menos sensível que a espécie animal na qual o produto foi testado ou quando o efeito observado é reversível ou pouco severo..$^{22,23}$

Dentre os parâmetros de ingestão crônica segura estimados para o homem estão a IDA, também chamada de dose de referência pelo $\mathrm{EPA},{ }^{25}$ a ingestão diária tolerável máxima provisória (Provisional Maximum Tolerable Daily Intake - PMTDI) e a ingestão tolerável semanal provisória (Provisional Tolerable Weekly Intake - PTWI). 
Esses parâmetros representam a quantidade da substância presente no alimento e/ou água que pode ser ingerida diariamente ao longo da vida sem que ocorram efeitos adversos à saúde. ${ }^{26} \mathrm{~A}$ IDA é normalmente definida para aditivos alimentares, drogas veterinárias e pesticidas, substâncias cuja concentração nos alimentos pode ser controlada pelas autoridades reguladoras. ${ }^{23}$ Para contaminantes, parâmetros de ingestão crônica segura são a PMTDI e a PTWI (para substâncias com potencial de acumulação no organismo). Nesse caso, o termo tolerável significa permissibilidade, não a aceitabilidade para a ingestão de contaminantes, cuja associação com os alimentos não pode ser evitada ou totalmente controlada. ${ }^{23,27}$

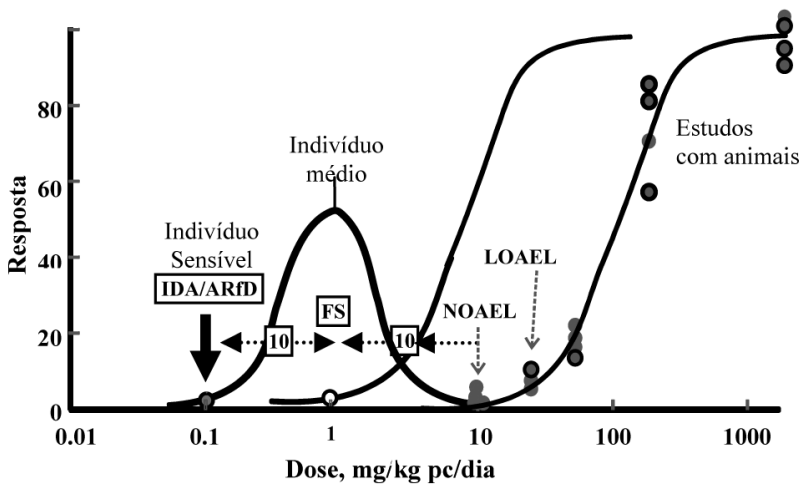

Figura 2. Estimativa de IDA ou ARfD a partir de experimentos com animais de laboratório

Somente a partir da década de 1990 que a necessidade de se acessar o risco da exposição aguda a substâncias químicas na dieta foi reconhecida internacionalmente, especificamente com relação à exposição a pesticidas. ${ }^{28}$ A Dose de Referência Aguda (Acute Reference Dose - ARfD) indica a quantidade de uma substância presente no alimento e/ou água que pode ser ingerida num período de $24 \mathrm{~h}$ ou menos sem que haja apreciável risco para a saúde do consumidor. ${ }^{22,29}$ A maioria dos princípios aplicáveis para estimar a IDA são também aplicados para estimar a ARfD, nesse caso utilizando preferencialmente os estudos críticos de curta duração. Em geral, o estabelecimento de ARfD é considerado não necessário para pesticidas cujos estudos toxicológicos indicariam um valor acima de 1 ou $5 \mathrm{mg} / \mathrm{kg}$ pc. ${ }^{29}$ Pesticidas organofosforados e carbamatos, que apresentam alta toxicidade aguda via inibição da acetilcolinesterase, normalmente apresentam ARfD menores que $0,1 \mathrm{mg} / \mathrm{kg} \mathrm{pc} .^{22}$

Enquanto para a maioria das substâncias os estudos com animais de laboratório são a única fonte de dados para o estabelecimento da ingestão segura, a avaliação de alguns contaminantes pode incluir outras fontes de informação. Um exemplo recente foi a avaliação conduzida pelo JECFA para estimar ingestão segura de metil mercúrio, a forma mais tóxica desse metal, por mulheres em idade reprodutiva com o objetivo de proteger o desenvolvimento fetal. ${ }^{30}$ Nessa avaliação, além de estudos com animais, dados de estudos epidemiológicos em humanos, de consumo de peixe contaminado, e de níveis de mercúrio em material biológico de mães expostas também foram utilizados para estimar o PTWI.

A Tabela 2 mostra alguns parâmetros de ingestão segura estabelecidos internacionalmente pelo JECFA e JMPR. No Brasil, a ANVISA estabelece IDAs para os pesticidas registrados no país e adota os parâmetros estabelecidos internacionalmente para as outras categorias de substâncias. ${ }^{5}$ Parâmetros de ingestão segura não são valores estáticos e definitivos, mas refletem os dados dos estudos toxicológicos avaliados durante o processo de caracterização da relação dose/resposta. Desta maneira, diferentes agências ou países podem, em momentos distintos, diante de outros estudos toxicológicos, de outras fontes de informação e/ou aplicando diferentes fatores de segurança chegar a parâmetros de ingestão segura distintos para uma mesma substância.

\section{Substâncias sem limiar de dose para efeito adverso- carcinogênicas e genotóxicas}

O processo da carcinogênese pode ser caracterizado por duas etapas principais: a primeira, que inicia o processo, envolve substâncias que reagem covalentemente com o DNA, ou são bioativadas a metabólitos que o fazem, causando mutações genéticas. A segunda envolve compostos que facilitam o crescimento de células alteradas geneticamente, contribuindo para o desenvolvimento de células neoplásticas. ${ }^{31}$ No último caso, assume-se que exista um nível de exposição abaixo do qual nenhum efeito adverso significante será induzido (NOAEL). Para substâncias carcinogênicas e genotóxicas, envolvidas na primeira etapa da carcinogênese, considera-se que não

Tabela 2. Parâmetros de ingestão segura estabelecidos pelo JECFA e JMPR

\begin{tabular}{|c|c|c|c|}
\hline Categoria & Substância & Parâmetro, $\quad \mu \mathrm{g} / \mathrm{kg} \mathrm{pc}$ & Estabelecida pelo $^{1}$ \\
\hline \multirow[t]{2}{*}{ Metal pesado } & $\begin{array}{l}\text { Mercúrio (total) } \\
\text { Metil mercúrio }\end{array}$ & $\begin{array}{c}5(\text { PTWI }) \\
3,3(\text { PTWI }) \\
1,6^{2}(\text { PTWI })\end{array}$ & $\begin{array}{l}\text { JECFA } 1978 \\
\text { JECFA } 2004\end{array}$ \\
\hline & Chumbo & 25 (PTWI) & JECFA 1999 \\
\hline \multirow[t]{2}{*}{ Pesticida } & Acefato & $\begin{array}{l}0-30(\text { IDA }) \\
100(\text { ARfD })\end{array}$ & JMPR 2005 \\
\hline & Mancozeb & $0-30(\mathrm{IDA})$ & JMPR 1993 \\
\hline \multirow[t]{2}{*}{ Droga veterinária } & Neomicina & 0-60 (IDA) & JECFA 1998 \\
\hline & Eritromicina & $0-0,7$ (IDA) & JECFA 1998 \\
\hline \multirow[t]{2}{*}{ Aditivo } & Sacarina & 0-5000 (IDA) & JECFA 1993 \\
\hline & Ácido benzoico & $0-5000(\mathrm{IDA})$ & JECFA 1996 \\
\hline \multirow[t]{2}{*}{ Micotoxina } & Fumonisinas & 2 (PMTDI) & JECFA 2001 \\
\hline & Ocratoxina A & 0,1 (PTWI) & JECFA 2001 \\
\hline
\end{tabular}

${ }^{1}$ Monografias do JMPR: http://www.fao.org/agriculture/crops/core-themes/theme/pests/ pm/jmpr/jmpr-rep/en; Mononografias do JECFA:http://www.inchem.org/pages/jecfa.html; ${ }^{2}$ mulheres em idade reprodutiva 
existe uma dose mínima de exposição para iniciar o modo de ação, isto é, em princípio, a exposição a uma única molécula pode levar a uma alteração genética e iniciar todo o processo., ${ }^{9,16}$ A flatoxina B1, por exemplo, micotoxina carcinogênica ao homem, ${ }^{32}$ inicia o processo da carcinogênese pela formação de seu epóxido. Em seguida, o nitrogênio (nucleófilo) da base guanina do DNA ataca o epóxido (eletrófilo) formando o aduto de DNA (Figura 3).
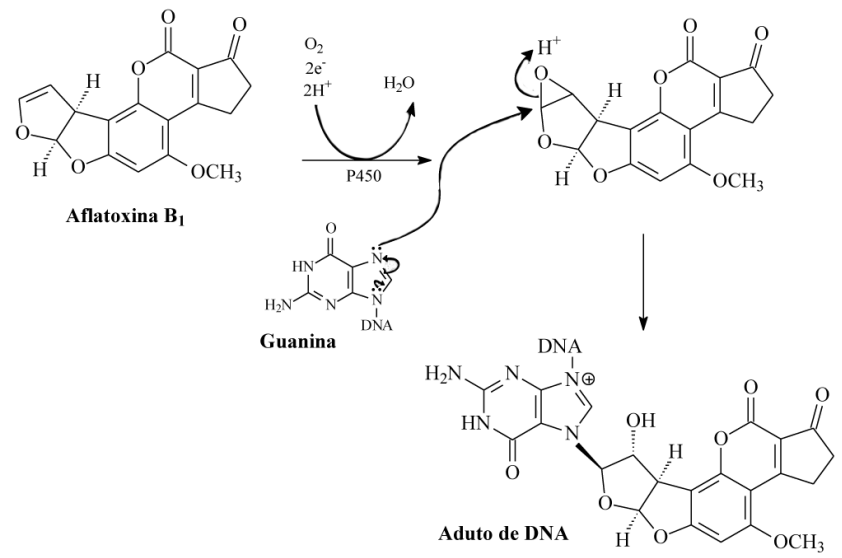

Figura 3. Reação da aflatoxina $B$, catalisada pela enzima mono-oxigenase do complexo citocromo P450 na formação do aduto de DNA

Além das aflatoxinas, substâncias carcinogênicas e genotóxicas presentes na dieta incluem aquelas produzidas durante o processamento e/ou estocagem dos alimentos, como os hidrocarbonetos policíclicos aromáticos (HPAs), a acrilamida e as nitrosaminas (Tabela 1). O grande desafio relacionado à exposição humana a estas substâncias deve-se ao fato de que a sua presença nos alimentos não pode ser totalmente eliminada ou evitada. Nenhuma substância registrada como aditivo, pesticida ou droga veterinária é reconhecidamente carcinogênica e genotóxica.

Atualmente, não há um consenso internacional sobre qual a melhor estratégia para se avaliar o risco a substâncias carcinogênicas e genotóxicas. Em princípio, se assume que existe uma relação linear entre risco e exposição; modelos matemáticos lineares são utilizados para se extrapolar dados experimentais de incidência de tumores em animais para doses que corresponderiam ao risco estimado no homem. Uma estratégia seria determinar a inclinação dessa curva doseresposta. O fator de inclinação seria definido como o limite superior da estimativa do risco por incremento da dose, que pode ser usado para estimar a probabilidade do risco para diferentes níveis de exposição. ${ }^{9,16,20}$ Nesse caso, um nível aceitável de risco pode ser definido como o nível de exposição associado a um risco de câncer de 1 em 1 milhão de pessoas $\left(1 / 10^{6}\right)$ ou 1 câncer em cem mil pessoas $\left(1 / 10^{5}\right)$.

Alternativamente, pode se determinar o fator de potência carcinogênica (q), que indica o número de casos adicionais de câncer devido a certo nível de exposição. Para as aflatoxinas, o fator de potência carcinogênica estimado pelo JECFA ${ }^{33}$ foi de 0,01 câncer/100.000 habitantes/ano/ng aflatoxina/kg pc/dia. Para populações com alta prevalência do vírus da hepatite $\mathrm{B}$, o fator q foi de 0,3 câncer $/ 100.000$ habitantes/ano/ng aflatoxina/ $\mathrm{kg}$ pc/dia. Esses fatores foram estimados a partir de estudos com animais de laboratório, estudos epidemiológicos em humanos e presença de indicadores biológicos de exposição na urina de indivíduos expostos.

\section{Benchmark Dose (BMD)}

O conceito de BMD foi originalmente proposto em $1984^{34}$ como uma alternativa ao uso de NOAEL/LOAEL para derivação dos níveis seguros de exposição humana. Enquanto NOAEL e LOAEL são doses discretas de um estudo, a estimativa de BMD envolve modelagem matemática da curva de dose-resposta para interpolar uma dose estimada que corresponda a um nível particular de resposta (p.ex., a dose que causou um aumento de $10 \%$ na incidência de tumores - BMD10). Normalmente, a incerteza desta interpolação também é estimada e o limite de confiança inferior desta dose denominado BMDL (benchmark dose lower confidence limit). ${ }^{35}$ Enquanto o NOAEL depende do desenho do experimento (i.e., pode ser maior ou menor dependendo da menor dose testada no estudo), o uso de BMD elimina qualquer limitação relacionada ao experimento e diminui a necessidade de se aplicarem fatores de segurança adicionais. ${ }^{36}$

A BMD pode ser usada em modelos de dose-resposta para todos os tipos de substâncias e endpoints, incluindo substâncias carcinogênicas e genotóxicas, independente da suposição de linearidade ou não da curva dose-resposta. Tal estratégia tem sido utilizada com frequência para o estabelecimento de doses de referência (RfD) para várias substâncias pela agência de proteção ambiental americana. ${ }^{37} \mathrm{O}$ EPA disponibiliza livremente no seu site (http://www.epa.gov/ncea/ bmds.htm) software que possibilita estimar a BMD a partir de dados experimentais. O uso de BMD na caracterização do risco da exposição humana a substâncias químicas será discutido posteriormente.

\section{Avaliação da exposição na dieta}

Avaliação da exposição é definida como a estimativa qualitativa e/ ou quantitativa da ingestão provável de agentes biológicos, químicos ou físicos via alimento, bem como a exposição de outras fontes, se relevante. ${ }^{37}$ Para estimar a exposição humana às substâncias químicas presentes nos alimentos são necessários três dados essenciais: a concentração da substância no alimento ( $\mathrm{mg} / \mathrm{kg})$, o consumo do alimento $(\mathrm{kg})$ e o peso corpóreo $(\mathrm{kg})$ (individual ou da população em estudo). A estimativa da exposição, dada em $\mathrm{mg} / \mathrm{kg}$ peso corpóreo, pode ser definida de uma maneira geral pela Equação 2

Exposição $=\frac{\text { Concentração da substância X consumo do alimento }}{\text { peso corpóreo }}$

A forma de obtenção dos dados a serem inseridos na Equação 2 depende primariamente dos propósitos da avaliação do risco, se a exposição é crônica ou aguda e do quão precisa e detalhada a estimativa deve ser. ${ }^{38}$ Além disso, a estimativa pode ser direcionada à população geral ou a determinados subgrupos populacional, como crianças. ${ }^{39}$ Em todos os casos, as incertezas envolvidas no cálculo da ingestão dependerão das incertezas envolvidas em cada um dos dados inseridos na Equação 2.

\section{Concentração da sustância no alimento}

Vários fatores influenciam os dados de concentração de uma substância no alimento, incluindo o processo de amostragem e coleta das amostras e o método analítico utilizado, sua precisão, exatidão, limite de detecção (LOD) e/ou quantificação (LOQ). A fonte dos dados de concentração deve fornecer valores confiáveis, caso contrário o resultado da avaliação da exposição poderá apresentar um alto grau de incerteza.

A avaliação da exposição humana aos aditivos, pesticidas e drogas veterinárias pode ocorrer quando se quer avaliar a exposição potencial antes da substância ser registrada para uso (pré-registro), ou depois da mesma já estar presente nos alimentos disponíveis para consumo (pós-registro). No caso de contaminantes, o nível da substância no alimento não pode ser totalmente controlado/eliminado e a estimativa da exposição subsidia o estabelecimento de limites máximos esperados/permitidos nos alimentos. Dependendo do alvo do estudo, diferentes bases de dados podem ser empregadas como parâmetro de concentração da substância no alimento. 
O Limite Máximo (LM) representa a quantidade máxima de um aditivo ou contaminante permitida legalmente no alimento. Para aditivos, os LM são estabelecidos durante o processo de registro e, normalmente, são sugeridos pelo fabricante para se obter um efeito tecnológico desejado. Adicionalmente, níveis de aditivos reportados na embalagem do alimento podem ser utilizados como parâmetro de concentração na avaliação da exposição. No caso de contaminantes, LM são estabelecidos a partir dos níveis naturalmente encontrados no alimento, supondo que o mesmo foi produzido de acordo com as boas práticas agrícolas e/ou de manufatura. Em princípio, LM de contaminantes refletem o menor nível da substância que pode ser alcançado sem que o alimento tenha que ser retirado do comércio. ${ }^{40}$

Limite Máximo de Resíduos (LMR) é a quantidade máxima de resíduos de um pesticida ou de uma droga veterinária permitida no alimento de origem vegetal e/ou animal, estabelecidos a partir dos estudos supervisionados de campo. Estudos desse tipo fornecem dados de resíduos de pesticidas e drogas veterinárias aos governos durante o processo de registro para subsidiar o estabelecimento de LMR nacionais, ou ao JMPR para recomendação de LMR ao Codex Alimentarius.

Em estudos de monitoramento, amostras de alimentos coletadas aleatoriamente no comércio são analisadas. Quando comparados ao LM e LMR, esses dados refletem melhor os níveis das substâncias encontradas nos alimentos comercializados. Nestes estudos, as amostras a serem analisadas devem representar o melhor possível a situação a ser avaliada, sendo necessário observar variáveis como quantidade, local de coleta e origem da amostra.

Uma limitação encontrada no uso de limites legais estabelecidos ou de dados de monitoramento, como parâmetros de concentração da substância para cálculo da ingestão, é que os mesmos refletem aqueles encontrados nos alimentos como comercializados, não como consumidos. O processamento do alimento, como descasque, lavagem e/ou cozimento, pode alterar o nível das substâncias presente e/ou sua natureza química. O processamento normalmente leva a uma diminuição dos níveis de resíduos e contaminantes nos alimentos devido a sua degradação química, com consequente diminuição da exposição e risco. Algumas exceções incluem o processo de desidratação, quando a concentração da substância aumenta no produto final, ou quando a degradação da substância leva a um composto mais tóxico que o original (ex., formação de etilenotiureia a partir de fungicidas etilenobisditiocarbamatos).

Em estudo de dieta total (EDT), os alimentos são processados antes da análise. Então, frutas com casca não comestível são descascadas e somente a polpa analisada; os alimentos normalmente consumidos cozidos são preparados de acordo com procedimentos padrões antes da análise. EDTs fornecem a estimativa mais próxima dos níveis de substâncias químicas presentes nos alimentos no momento do consumo, refletindo melhor a exposição. ${ }^{41}$

A metodologia utilizada na análise de resíduos e contaminantes em amostras de alimentos deve ser validada de acordo com procedimentos internacionalmente aceitos. ${ }^{42-44}$ Dados provenientes de laboratórios que possuem o sistema de gestão da qualidade implementado (ISO/IEC 17025) possuem alta credibilidade, uma vez que os procedimentos adotados já foram avaliados por órgãos competentes. A metodologia analítica selecionada deve ser a que melhor se aplica ao analito e aos objetivos do estudo, e nem sempre o método mais sensível é necessariamente a melhor escolha. Por exemplo, aditivos alimentares normalmente não estão presentes nos alimentos em concentrações baixas, já que nesses níveis eles não agregam nenhum benefício tecnológico. Para esses compostos, técnicas com sensibilidade moderada são suficientes para fornecer dados para a condução de estudos de avaliação da exposição. Em outros casos, métodos rápidos e robustos são necessários para responder a uma demanda emergencial que necessite ações de gerenciamento de risco rápidas. Métodos multirresíduos são normalmente necessários no caso de pesticidas, principalmente em programas de monitoramento, já que o leque de substâncias que podem estar presentes nos alimentos pode ultrapassar 200 compostos. ${ }^{45}$ Análise de contaminantes ambientais e estudos de dieta total normalmente exigem métodos analíticos com alta sensibilidade, já que os analitos podem estar presentes nos alimentos em concentrações menores que $10 \mu \mathrm{g} / \mathrm{kg}$. ${ }^{46}$

Um aspecto importante que deve ser observado nos dados obtidos em laboratório é como lidar com amostras que não apresentaram níveis detectáveis/quantificáveis do analito, isto é, quando os resultados são reportados como menor que o LOD ou LOQ. Essa questão tem sido largamente considerada por vários autores, sendo consenso que o procedimento de escolha deve ser conservativo o suficiente para manter a precaução em relação a substâncias tóxicas, mas também cientificamente justificável, ${ }^{38,47}$ a não ser que existam evidências suficientes para se ter certeza de que nenhum resíduo da substância é esperado no alimento. Um procedimento largamente aplicado é considerar que substâncias reportadas como menores que o LOQ apresentem níveis correspondentes a 0,5 x LOQ. ${ }^{38,48,49}$ Outra estratégia, aplicada principalmente no caso de contaminantes, é considerar os dois limites da estimativa: o inferior como zero para amostras não detectadas (< LOD) e o superior, com amostras nos níveis do LOD ou LOQ. ${ }^{39}$ É claro que a incerteza envolvida em qualquer estratégia será maior quanto menor for a sensibilidade do método analítico utilizado.

\section{Consumo de alimentos e peso corpóreo}

Existem quatro tipos de dados que podem ser usados para acessar o consumo de alimentos de uma população: dados de suprimento de alimentos, de disponibilidade de alimento no domicílio, de consumo individual de dieta duplicada. A escolha da fonte de dados irá depender principalmente dos objetivos do estudo, dos alimentos de interesse, da necessidade de acessar a exposição de grupos específicos da população e das fontes disponíveis. Idealmente, dados de consumo devem estar diretamente relacionados ao de peso corpóreo de um indivíduo ao qual o consumo está associado; no caso desse dado não estar disponível, o peso médio da população em estudo pode ser usado. ${ }^{37}$

Dados de suprimentos de alimentos são calculados a partir dos balancetes da produção agropecuária do país, que leva em consideração a produção anual do alimento, importações, exportações, perda no campo e uso na pecuária e indústria. $\mathrm{O}$ resultado reflete a média de disponibilidade do alimento não processado disponível por habitante. ${ }^{50}$ As 13 dietas cluster do GEMs/Food (Global Environmental Monitoring System) são atualmente utilizadas pelo JMPR e pelo JECFA para cálculo de exposição crônica a substâncias químicas no âmbito internacional. As dietas foram estimadas a partir de dados de suprimentos de alimentos reportados à FAO por 183 países entre 1997 e 2001, e agrupa os países de acordo com a disponibilidade nacional de 19 alimentos marcadores. ${ }^{50}$ Nesse contexto, o Brasil foi incluído na dieta $\mathrm{K}$, caracterizada pelo alto consumo de aves, que inclui também outros 17 países das Américas do Sul e Central. No âmbito internacional, considera-se o peso médio corpóreo da população de 60 ou $55 \mathrm{~kg}$, dependendo da dieta. Entre as limitações desses dados está a impossibilidade de acessar o consumo de alimentos de subgrupos mais sensíveis da população, como crianças, idosos e gestantes. ${ }^{38,51}$

Dados de disponibilidade de alimento no domicílio são obtidos nacionalmente a partir de pesquisas nos domicílios que reportam a quantidade de cada alimento adquirida pela família durante um determinado período. Esses dados, em geral, não informam a distribuição de consumo entre os indivíduos e não consideram o consumo fora do domicílio nem a quantidade de alimento desperdiçada. ${ }^{52,53} \mathrm{No}$ 
Brasil, o Instituto Brasileiro de Geografia e Estatística (IBGE) conduz periodicamente a coleta de dados de disponibilidade de alimento por meio da Pesquisa de Orçamento Familiar (POF). Nesta pesquisa, domicílios pesquisados reportam durante sete dias consecutivos a quantidade de cada alimento aportado ao domicílio, seja pela compra, doação ou produção própria.$^{54}$ Outros dados coletados incluem idade, sexo e peso corpóreo de cada indivíduo do domicílio. Na POF 20082009, a aquisição de dados de consumo individual de indivíduos com idade a partir de 10 anos, moradores de $30 \%$ dos 60.000 domicílios pesquisados também é acessada. ${ }^{58}$ Dados da POF têm sido utilizados, entre outros, por nutricionistas para acessar a disponibilidade de nutrientes na população brasileira ${ }^{55}$ e para avaliar a exposição a substâncias químicas na dieta. ${ }^{56,57}$

Dados de consumo individual é a fonte ideal para avaliar a exposição humana a substâncias químicas na dieta, já que podem acessar o consumo de subgrupos específicos da população e estabelecer a relação consumo/peso corpóreo para cada indivíduo. Entre as metodologias para coleta desses dados está o registro individual de consumo durante um período (normalmente entre 1 e 7 dias), o recordatório $24 \mathrm{~h}$, onde o individuo reporta o tipo e quantidade de alimentos consumidos nas últimas $24 \mathrm{~h}$, e o Questionário de Frequência Alimentar (QFA) constituído de uma lista estruturada de alimentos com o objetivo de acessar sua frequência de consumo diário ou semanal. ${ }^{38,59}$

Em estudos de dieta duplicada, os indivíduos coletam uma segunda porção de todos os alimentos que consomem durante certo período (normalmente de 1 a 7 dias), incluindo o que é consumido fora do domicílio. Os alimentos são pesados e as porções são analisadas em laboratório para as substâncias de interesse. Esses estudos fornecem ao mesmo tempo dados de consumo por peso corpóreo e de concentração para uma dada população/substância. Pela sua alta complexidade e custo, estudos de dieta duplicada são normalmente restritos a grupos específicos da população, principalmente crianças. ${ }^{60-62}$

\section{Exposição cumulativa e exposição agregada}

A exposição simultânea a várias substâncias químicas na dieta (cumulativa) e/ou advinda de várias fontes de exposição (agregada), e suas consequências para a saúde humana, tem sido objeto de preocupação de órgãos reguladores e da população em geral.

Os efeitos tóxicos de duas ou mais substâncias no organismo podem ser independentes, aditivos ou interativos (como sinergismo, potenciação ou antagonismo) ${ }^{63,64} \mathrm{O}$ efeito aditivo ocorre quando os compostos individuais de uma mistura possuem o mesmo mecanismo de ação tóxica (grupo de compostos com mecanismo comum - GMC), diferindo apenas da potência desse efeito. ${ }^{49}$ Nesse caso, o efeito final da exposição a um GMC é equivalente à soma dos efeitos de cada composto do grupo corrigido para sua potência tóxica equivalente. A exposição a um GMC é chamada de cumulativa.

Diferentes métodos têm sido utilizados para acessar a toxicidade final de GMCs, incluindo índices de dano, de ponto de partida, de exposição cumulativa, margem de exposição combinada e fator de equivalência tóxica. ${ }^{65-67} \mathrm{O}$ fator de equivalência tóxica (FET) foi primeiramente proposto na década de 1980 pelo EPA $^{65}$ e aplicado para o grupo das dioxinas e compostos similares (dibenzofuranos e bifenilas policlorados; Tabela 1), que agem no organismo como agonistas de receptores de hidrocarboneto de arila. ${ }^{66}$ Nesse método, o FET de cada composto do grupo foi calculado normalizando sua toxicidade em relação ao composto indicador, a 2,3,7,8-tetraclorobenzo-p-dioxina (TCDD). O equivalente tóxico total foi definido como a soma dos produtos da concentração de cada composto do grupo numa amostra multiplicado pelo seu FET, e expresso como TCDD. ${ }^{67}$ Valores de FET para esse GMC são frequentemente avaliados à luz de novos dados toxicológicos. ${ }^{68}$ Esta metodologia foi posteriormente aplicada a pesticidas, com a introdução do fator de potência tóxica, para avaliar a exposição cumulativa de crianças a inseticidas organofosforados, ${ }^{69,70}$ sendo hoje empregada rotineiramente pelo EPA para avaliar a exposição cumulativa a esse GMC. ${ }^{71}$ Outros autores incluíram nesse grupo os inseticidas carbamatos, também inibidores da acetilcolinesterase. ${ }^{72-74}$ Porém, um estudo amplo que confirme que esses compostos pertencem ao GMC dos inseticidas organofosforados ainda não foi realizado.

A possibilidade da ação interativa de aditivos alimentares que apresentem o mesmo órgão alvo de ação tóxica foi avaliada por Groten et al..$^{75}$ e excluída para a maioria dos 65 aditivos estudados. Dentre as possíveis interações identificadas está o efeito na tireóide da eritrosina, tiabendazol e nitrato e o efeito no fígado da curcumina, tiabendazol, galato de propila e BHT. Apesar dos autores concluírem que a interação entre aditivos no organismo não representa uma preocupação para a saúde humana devido à baixa exposição, o grande número dessas substâncias utilizadas pela indústria de alimentos requer estudos adicionais que avaliem esta possibilidade em todos os casos.

A avaliação da exposição agregada a substâncias químicas considera as várias fontes de exposição possíveis de ocorrer além do consumo de alimentos, como de água e solo, e a exposição dérmica e inalatória em ambientes residenciais ou exteriores. ${ }^{76}$ Esses estudos são complexos e exigem normalmente modelos matemáticos que simulem situações onde mais de uma via de exposição ocorra ao mesmo tempo. Clayton et al. ${ }^{77}$ avaliaram a exposição cumulativa e agregada aos inseticidas organofosforados de 102 crianças no estado americano de Minnesota. Várias fontes de dados foram utilizadas para acessar a exposição, incluindo a concentração das substâncias no ar e poeira dentro e fora das residências e na água potável, dados de dieta duplicada e concentração de metabólitos de pesticidas em amostras de urina dos indivíduos do estudo.

\section{Modelos para cálculo da exposição (ingestão)}

De maneira geral, dois modelos podem ser utilizados para o cálculo da exposição como descrito na Equação 2 - o modelo determinístico e o probabilístico. A escolha do modelo depende de vários fatores, incluindo o objetivo do estudo, os dados disponíveis e a exatidão exigida nos resultados.

No modelo determinístico, valores fixos, pontuais, de concentração e consumo são utilizados no cálculo da ingestão, como a média, mediana, 97,5 percentil ou valor máximo. ${ }^{40}$ As grandes vantagens desse método são a rapidez e a simplicidade dos cálculos. Por outro lado, esse modelo presume que todos os indivíduos de uma população em estudo possuem o mesmo peso corpóreo, consomem a mesma quantidade de um alimento que contém sempre a mesma concentração da substância de interesse. Apesar dos resultados obtidos no modelo determinístico serem facilmente comunicados e compreendidos pelas várias partes interessadas, os valores utilizados no cálculo são conservadores e a exposição estimada reflete uma situação irreal. Adicionalmente, eles não fornecem informação da faixa dos níveis possíveis de exposição que pode ocorrer em toda a população, limitando a identificação do cenário de exposição que pode representar um risco potencial e da exposição de grandes consumidores. ${ }^{38-40,78}$ Apesar das limitações, a avaliação determinística da exposição é importante para um diagnóstico inicial de uma situação de risco, indicando a necessidade de gerar dados adicionais para refinar o estudo (por exemplo, quando o mesmo é conduzido utilizando disponibilidade de alimentos no domicílio e/ou limites legais da substância no alimento) e/ou de se aplicar o modelo probabilístico.

O modelo probabilístico de avaliação da exposição envolve a descrição das variáveis de consumo/peso corpóreo e concentração em termos de distribuição para caracterizar sua variabilidade e/ 
ou incerteza. ${ }^{38,80} \mathrm{~A}$ exposição pode ser simulada retirando valores aleatórios de cada variável na curva de distribuição utilizando modelos matemáticos adequados. Existe uma variedade de softwares disponíveis para aplicação desses modelos, que utilizam principalmente técnicas probabilísticas de Monte Carlo (Figura 4). Nos Estados Unidos os modelos DEEM/Calendex, CARES e Lifeline são utilizados pelo EPA. ${ }^{79} \mathrm{Na}$ Europa, os modelos disponíveis incluem o MCRA (Holanda), CREMe (Irlanda), UniHB (Alemanha) e o CSL (Inglaterra). ${ }^{49}$
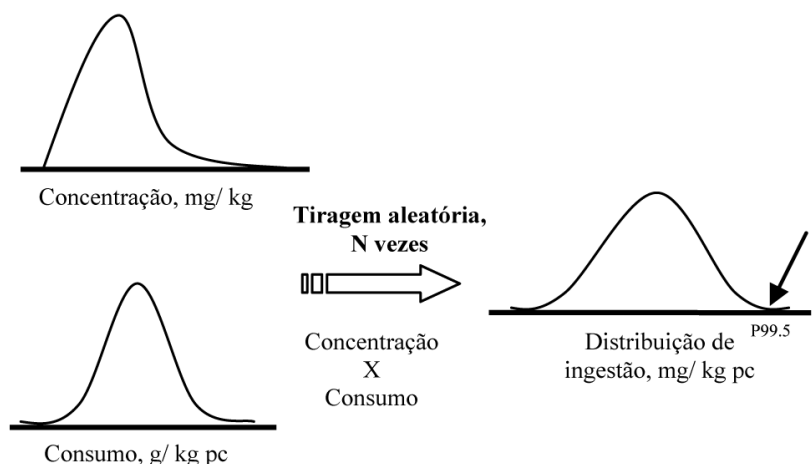

Figura 4. Modelo probabilístico para estimar a exposição humana a substâncias químicas na dieta

$\mathrm{Na}$ avaliação probabilística, a curva de distribuição resultante representa um panorama de exposição mais realista, fornecendo ao gerenciador de risco maior subsídio para tomada de decisões. ${ }^{81}$ Adicionalmente, existe a possibilidade de avaliar o impacto de cada parâmetro na avaliação (análise de sensibilidade), bem como as incertezas de cada resultado. Dessa maneira, a exposição em vários percentis da curva de distribuição pode ser acessada, bem como a incerteza associada a esta estimativa. ${ }^{82}$ Métodos probabilísticos, porém, só podem ser utilizados quando dados brutos de consumo/ peso corpóreo e de concentração estão disponíveis, o que limita sua aplicação. O uso dessa ferramenta exige do avaliador conhecimentos de como lidar com as limitações e incertezas do modelo utilizado. $\mathrm{O}$ método probabilístico é o método de escolha para estimar a exposição cumulativa e agregada a resíduos e contaminantes. ${ }^{49,71,76}$

\section{A exposição crônica}

A exposição crônica a substâncias químicas na dieta ocorre diariamente, por um período longo, inclusive durante toda a vida. O cálculo da Ingestão Diária, em mg/kg peso corpóreo/dia, de uma determinada substância ou GMC é feito considerando o somatório da ingestão pelo consumo de todos os alimentos da dieta da população em estudo, de acordo com a Equação 3,

Ingestão $=\frac{\Sigma(\mathrm{Ri} \times \mathrm{Ci})}{\text { peso corpóreo }}$

onde R é o valor da concentração da substância ou GMC, no alimento $i$, em $\mathrm{mg} / \mathrm{kg}$ e $\mathrm{C}$ é o consumo diário, em $\mathrm{kg}$, desse alimento pela população/indivíduo em estudo. ${ }^{26} \mathrm{Na}$ metodologia determinística, normalmente se consideram valores médios desses parâmetros no cálculo, já que eles refletem melhor as variações de exposição que podem ocorrer durante um período longo.

A estimativa da ingestão crônica dependerá da disponibilidade e da qualidade dos dados envolvidos no seu cálculo; quanto mais próximos da realidade esses dados, mais significativo será o resultado. Por exemplo, a Ingestão Diária Teórica Máxima (IDTM) para pesticidas, drogas veterinárias ou aditivos alimentares é estimada utilizando o limite máximo permitido pela legislação para cada com- posto/alimento. Em geral, essa estimativa é bastante conservadora, pois presume que todos os alimentos contêm a substância no nível do limite máximo e que o indivíduo os consome diariamente durante toda a vida. No caso de pesticidas e drogas veterinárias, presume-se ainda que não exista nenhuma degradação do composto durante o transporte, armazenamento e processamento desses alimentos.

\section{A exposição aguda}

A significância da exposição aguda a pesticidas foi reconhecida no início da década de 1990, depois de relatos de intoxicação pelo consumo de alimentos altamente contaminados devido ao uso inadequado desses produtos no campo. ${ }^{83,84}$ Mais recentemente, a intoxicação humana com inseticidas organofosforados e carbamatos presentes na dieta foi reportada. ${ }^{85,86}$

Enquanto a avaliação do risco crônico estima a ingestão média pelo consumo de alimento durante um longo período, a avaliação do risco agudo avalia a exposição pelo consumo de uma única refeição ou durante $24 \mathrm{~h}$. Nesse caso, um indivíduo pode consumir uma porção muito maior de um determinado alimento durante um dia do que a média consumida durante a vida e, adicionalmente, a porção pode conter uma determinada substância em níveis muito maiores do que os valores médios normalmente utilizados para avaliar uma exposição crônica. ${ }^{26,87} \mathrm{O}$ objetivo é avaliar o risco do indivíduo de ingerir num só dia uma grande quantidade de uma substância pelo consumo de uma grande quantidade de alimento altamente contaminado. Dessa forma, os valores de consumo/peso corpóreo e concentração são representados por valores extremos, ou altos percentis (97,5 $\mathrm{P}$ ou maior).

Duas metodologias podem ser utilizadas nessa estimativa. A primeira utiliza a Equação 3 e o modelo probabilístico, selecionando os mais altos percentis de ingestão. A segunda metodologia, descrita para ser utilizada com o modelo determinístico, considera o consumo de cada alimento separadamente, já que é remota a possibilidade de um indivíduo consumir num mesmo dia quantidades grandes de todos os alimentos da dieta e que todos esses alimentos estejam altamente contaminados. A ingestão aguda de pesticidas pelo consumo de cada alimento é denominada IESTI (International ou National Estimated Short-Term Intake). A metodologia para o cálculo da IESTI, descrita inicialmente em 1997 e adotada posteriormente pelo JMPR, ${ }^{88}$ reconhece a existência da variabilidade de resíduos entre unidades individuais de um alimento de um mesmo lote. $\mathrm{O}$ fator de variabilidade é definido como a razão entre o valor referente ao 97,5 percentil dos valores de resíduos das unidades individuais e a média de resíduos encontrada no mesmo lote, sendo atualmente definido como $3 .{ }^{89,90}$ Esse fator indica que num lote de laranjas, por exemplo, existe uma unidade que apresenta uma concentração 3 vezes maior que a concentração média de todas as unidades presentes no lote. A metodologia para o cálculo da IESTI utiliza diferentes equações dependendo da massa da unidade (Unit - U) do alimento e de sua proporção em relação à maior porção consumida, isto é, se o consumo pode incluir mais de uma unidade (p.ex., laranja) ou é parte dela (p.ex., melancia). O consumo de alimento é representado pela maior porção (Large Portion - LP), que representa o consumo de 97,5 percentil dos consumidores. A concentração é dada pelo maior resíduo encontrado em amostras compostas (Highest Residue - HR), preferencialmente da parte comestível do alimento, de estudos supervisionados de campo. ${ }^{88}$

Quando U (kg) é menor que LP $(\mathrm{kg})$, assume-se que a primeira unidade do alimento a ser consumida possuirá a maior quantidade de resíduo e o resíduo encontrado na amostra composta (HR, $\mathrm{mg} / \mathrm{kg}$ ) é multiplicado pelo fator de variabilidade $v$. O que restou da LP para ser consumida virá de unidades que contenham resíduos no nível de HR (segunda metade do numerador, Equação 4). O cálculo da IESTI finaliza dividindo-se o resultado de concentração da substância na porção consumida do alimento pelo peso corpóreo $(\mathrm{kg})$. 


$$
\mathrm{IESTI}=\frac{(\mathrm{U} \times \mathrm{HR} \times \mathrm{v})+(\mathrm{LP}-\mathrm{U}) \times \mathrm{HR}}{\text { peso corpóreo }}
$$

Quando U é maior que LP, presume-se o consumo de parte da unidade do alimento com maior quantidade de resíduo (Equação 5)

$$
\text { IESTI }=\frac{\mathrm{LP} \times \mathrm{HR} \times v}{\text { peso corpóreo }}
$$

No caso de alimentos com $\mathrm{U}<25 \mathrm{~g}$, como grãos tratados pós-colheita, ovos e carne, não se aplica o fator de variabilidade na estimativa. Para alimentos processados, leites e grãos tratados pré-colheita, assume-se que o nível de resíduo corresponde ao valor mediano dos resíduos encontrados nos estudos supervisionados de campo (supervised trial median residue - STMR). Em todos os casos, o dado de consumo corresponde à maior porção LP. ${ }^{88}$

A metodologia para o cálculo da IESTI também tem sido utilizada para estimar a ingestão aguda nacional ou regional na Comunidade Européia. ${ }^{91} \mathrm{O}$ procedimento foi descrito para o caso dos pesticidas, mas os princípios podem ser considerados para as outras substâncias químicas.

No âmbito do JMPR, uma limitação importante no cálculo da IESTI refere-se aos dados de consumo, massa da unidade e peso corpóreo disponibilizados atualmente. Esses dados foram fornecidos pelos governos de 10 países, incluindo Austrália, África do Sul, França, Japão e Estados Unidos, e compilados pelo GEMs/Food ${ }^{89}$ Como as metodologias utilizadas para estimar os dados não foram fornecidas, as incertezas envolvidas em cada caso não são conhecidas. Adicionalmente, para alguns alimentos, os dados de consumo disponíveis podem não refletir o hábito alimentar dos grandes consumidores em alguns países.

\section{Caracterização do risco}

A caracterização do risco pode ser definida como a estimativa qualitativa ou, sempre que possível, quantitativa, incluindo as incertezas esperadas, da probabilidade de ocorrência de um efeito adverso de um dado agente num dado organismo ou população sob condições definidas de exposição. ${ }^{3}$

As metodologias utilizadas para caracterizar o risco variam de acordo com as características toxicológicas da substância, isto é, se a substância necessita de um limiar de dose no organismo para exercer sua ação tóxica (substâncias não genotóxicas) ou não (substâncias carcinogênicas e genotóxicas).

\section{Substâncias não genotóxicas}

Para se avaliar o risco da exposição a substâncias não genotóxicas, a ingestão é comparada ao parâmetro de ingestão segura; o risco pode existir quando a ingestão calculada ultrapassa esse parâmetro. ${ }^{26}$ Esse risco pode ser expresso em \% do parâmetro toxicológico como, por exemplo, em porcentagem da IDA numa exposição crônica (Equação 6). Nesse caso, o risco pode existir quando a porcentagem ultrapassa 100.

$\%$ IDA $=\frac{\sum \text { Ingestão }}{\text { IDA }} \times 100$

Para a exposição aguda aos pesticidas, a ingestão é comparada à ARfD, e a caracterização do risco pode ser feita considerando a ingestão total num alto percentil estimada com o método probabilístico ${ }^{77,78}$ ou para cada alimento separadamente, a partir do cálculo da IESTI. Nos últimos anos, vários pesticidas/alimentos avaliados pelo JMPR apresentaram a IESTI excedendo a ARfD. Nesses casos, mesmo que limites máximos de resíduos sejam estimados pelo JMPR, o Comitê de Resíduos de Pesticidas do Codex Alimentarius não os recomenda como LMR Codex. ${ }^{92}$

\section{Substâncias carcinogênicas e genotóxicas}

Dentre as metodologias disponíveis para caracterizar o risco da exposição a substâncias carcinogênicas e genotóxicas estão: 1) o princípio ALARA (as low as reasonably achievable), que indica a redução da exposição ao nível mais baixo que possa ser alcançado; 2) a extrapolação para doses de exposição aceitável/conhecida a partir de estudos de carcinogenicidade com roedores (estratégia utilizada pelo JECFA para aflatoxinas, como descrito anteriormente); 3) a aplicação do TTC (threshold of toxicological concern), que indica um valor único de exposição segura para todas as substâncias e, 4) o cálculo da Margem de Exposição (MOE) ${ }^{20,93}$ A MOE pode ser calculada a partir da Equação 7, sendo a BMDL, preferencialmente a BMDL10, identificada como ponto de referência toxicológico mais adequado para a estimativa.

$\mathrm{MOE}=\frac{\text { Referência toxicológica }}{\text { Exposição }}$

O conceito da MOE foi aplicado recentemente pelo JECFA ${ }^{94}$ para avaliar o risco da exposição humana à acrilamida, substância produzida durante o processamento de alimentos a altas temperaturas, como batata e produtos de panificação (Tabela 1). Quando dados disponíveis não permitem estimar a BDML10, a T25 (dose que induz tumores em $25 \%$ da população em estudo), pode ser utilizada como referência toxicológica. ${ }^{93}$ Adicionalmente, quando estudos de carcinogenicidade não estão disponíveis, a menor dose efetiva em estudos de genotoxicidade in vivo pode ser utilizada. MOE menores que 2.000, baseados em T25 e/ou BMDL foram estimados recentemente para acrilamida, ${ }^{93,94}$ aflatoxinas e dimetilnitrosamina. ${ }^{94}$

Um valor de MOE igual ou maior que 10.000 tem sido proposto como uma indicação de uma situação de risco pouco preocupante sob a ótica de saúde pública. ${ }^{20}$ Esse valor permite a: 1) diferença de toxicocinética e toxicodinâmica entre as espécies e a variabilidade humana, 2) a variabilidade individual humana no ciclo celular e reparo de DNA e 3) o fato de que o ponto de referência toxicológica representa a dose na qual o efeito adverso foi observado. Consideramos, porém, que este valor (10.000) esteja superestimado, já que a variabilidade humana foi prevista duplamente na sua estimativa. Segundo Barlow et al., ${ }^{20} \mathrm{a}$ MOE não é uma quantificação do risco, mas sua magnitude pode ser usada para classificar substâncias, indicar o nível de preocupação e estabelecer prioridades de ações para os gerenciadores de risco e para subsidiar os indivíduos a tomar decisões pessoais de estilo de vida. Os autores ressaltaram que vários aspectos precisam ser harmonizados para possibilitar o uso da MOE na caracterização do risco de substâncias carcinogênicas e genotóxicas na dieta, incluindo os critérios para caracterizar estas substâncias, as ferramentas computacionais para modelagem da dose-resposta, o uso apropriado de cenários de exposição, incluindo métodos probabilísticos, e como explicar e comunicar as incertezas da estimativa usando esta estratégia.

\section{CONCLUSÃO}

Os paradigmas do processo de avaliação do risco da exposição humana a substâncias químicas na dieta têm evoluído consideravelmente nos últimos anos, envolvendo pesquisadores de varias áreas do conhecimento, incluindo químicos orgânicos e analíticos, toxicologistas e estatísticos. A introdução de novos modelos biológicos e experimentais tem permitido a elucidação de mecanismo de ação tóxica de várias substâncias e a caracterização daquelas que apresen- 
tam limiar de dose de efeito e outras com propriedades carcinogênica e genotóxica. Sem dúvida, essa última categoria é a que coloca os maiores desafios para o futuro, já que nela se encontram as substâncias cuja presença no alimento não pode ser totalmente controlada ou eliminada, como aflatoxinas e acrilamida.

O Brasil ainda tem uma participação discreta na discussão dos paradigmas e metodologias utilizadas na avaliação do risco. Porém, vários estudos têm sido conduzidos para avaliar a exposição do brasileiro a substâncias químicas, principalmente relacionados a pesticidas, ${ }^{56,57,73,95-97}$ micotoxinas, ${ }^{98,99}$ metais, ${ }^{100-102}$ e aditivos. ${ }^{103,104} \mathrm{E}$ importante um maior envolvimento da comunidade científica do país nesta discussão, principalmente para subsidiar a ANVISA em suas ações de gerenciamento de risco da exposição e garantir alimento seguro para a população.

\section{REFERÊNCIAS}

1. Institute of Medicine; Food Safety Policy, Science, and Risk Assessment: Strengthening the Connection. Workshop Proceedings. Food Forum, Food and Nutrition Board. National Academy Press, Washington, DC, 2001.

2. National Research Council; Risk Assessment in the Federal Government: Managing the Process. Committee on the Institutional Means for Assessment of Risks to Public Health. National Academy Press, Washington, DC. 1983.

3. International Programme on Chemical Safety; Risk Assessment Terminology. Harmonization Project. WHO, Geneva, 2004.

4. World Health Organization; Risk Management and Food Safety. FAO Food and Nutrition Paper, $\mathrm{n}^{\circ}$ 65. Report of a Joint FAO/WHO Consultation. Rome, 1997.

5. http://www.anvisa.gov.br, acessada em Julho 2009 .

6. World Health Organization; Framework for the Provision of Scientific Advice on Food Safety and Nutrition. Geneva, 2007.

7. World Health Organization; Application of Risk Analysis to Food Standards Issues. Report of a FAO/WHO Expert Consultation. WHO/ FNU/FOS/95.3. Geneva, 1995.

8. Dybing, E.; Doe, J.; Groten, J.; Kleiner, J.; O’Brien, J.; Renwick, A. G.; Schlatter, J.; Steinberg, P.; Tritscher, A.; Walker, R.; Younes, M.; Food Chem. Toxicol. 2002, 40, 237

9. Edler, L.; Poirier, K.; Dourson, M.; Kleiner, J.; Mileson, B.; Nordmann, H.; Renwick, A.; Slob, W.; Walton, K.; Würtzen, G.; Food Chem. Toxicol. 2002, 40, 283.

10. European Chemicals Bureau; Technical Guidance Document on Risk Assessment. Part III. Cap 4: Use of (Quantitative) Structure Activity Relationships ((Q)SARs). 2003 European Commission Joint Research Centre, Italy.

11. World Health Organization; Evaluation of Certain Food Additives and Contaminants. Safety evaluation of flavoring agents. Forty-fourth report of the Joint FAO/WHO Expert Committee on Food Additives. WHO Technical Report Series 859. Geneva, 1995.

12. Cramer, G. M.; Ford, R. A.; Hall, R. L.; Food Cosmetics Toxicol. 1978, $16,255$.

13. Kroes, R.; Galli, C.; Munro, I.; Schilter, B.; Tran, L.; Walker, R.; Würtzen, G.; Food Chem. Toxicol. 2000, 38, 255.

14. Renwick, A. G.; Toxicol. Appl. Pharmacol. 2005, 207, 1585.

15. Valerio, L. G. Jr.; Arvidson, K. B.; Chanderbhan, R. F.; Contrera, J. F.; Toxicol. Appl. Pharmacol. 2007, 222, 1.

16. Environmental Protection Agency; Carcinogen Risk Assessment. Office of Research and Development. U.S. EPA/600/P-92/003C. Washington, DC. April 1996

17. Eisenbrand, G.; Pool-Zobel, B.; Baker, V.; Balls, M.; Blaauboer, B. J.; Boobis, A.; Carere, A.; Kevekordes, S.; Lhuguenot, J.-C.; Pieters, R.; Kleiner, J.; Food Chem. Toxicol. 2002, 40, 193.
18. Organization for Economic Co-operation and Development (OECD); Guidelines for the Testing of Chemicals 1993, Vol. 2, Section 4.

19. http://oberon.sourceoecd.org/vl=1889996/cl=17/nw=1/rpsv/cw/vhosts/ oecdjournals/1607310x/v1n4/contp1-1.htm, acessada em Julho 2009.

20. Barlow, S.; Renwick, A. G.; Kleiner, J.; Bridges, J. W.; Busk, L.; Dybing, E.; Edler, L.; Eisenbrand, G.; Fink-Gremmels, J.; Knaap, A.; Kroes, R.; Liem, D.; Muller, D. J.; Page, S.; Rolland, V.; Schlatter, J.; Tritscher, A.; Tueting, W.; Würtzen, G.; Food Chem Toxicol. 2006, 44, 1636.

21. van den Brandt, P.; Voorrips, L.; Hertz-Picciotto, I.; Shuker, D.; Boeing, H.; Speijers, G.; Guittard, C.; Kleiner, J.; Knowles, M.; Wolk, A.; Goldbohm, A.; Food Chem. Toxicol. 2002, 40, 387.

22. http://www.fao.org/agriculture/crops/core-themes/theme/pests/pm/jmpr/ jmpr-rep/en/, acessada em Julho 2009.

23. Herrman, J. L.; Younes, M.; Regul. Toxicol. Pharmacol. 1999, 30, S109.

24. Speijers, G. J.; Regul. Toxicol. Pharmacol. 1999, 30, S87. Review.

25. http://www.epa.gov/NCEA/iris/rfd.htm, acessada em Julho 2009.

26. World Health Organization; Food consumption and exposure assessment of chemicals, Report of a FAO/WHO Consulation. Geneva, Switzerland, 1997.

27. http://www.inchem.org/documents/ehc/ehc/ehc70.htm, acessada em Julho 2009.

28. http://www.inchem.org/documents/ehc/ehc/ehc170.htm, acessada em Julho 2009

29. Solecki, R.; Davies, L.; Dellarco, V.; Dewhurst, I.; Raj, M.; Tritscher, A.; Food Chem. Toxicol. 2005, 43, 1569.

30. World Health Organization; Evaluation of Certain Food Additives and Contaminants. Sixty-First Report of the Joint FAO/WHO Expert Committee on Food Additives. WHO Technical report series 922. Geneva, 2004.

31. Faustman, E. M.; Omenn, G. S. Em Casarett and Doull's Toxicology: The Basic Science of Poisons; Klaassen, C. D., ed.; McGraw-Hill: New York, 2005, cap 4.

32. International Agency for Research on Cancer (IARC); Naturally Occurring Aflatoxins (Group1). Summary of Data Reported and Evaluation, 1997.

33. http://www.inchem.org/documents/jecfa/jecmono/v040je16.htm, acessada em Julho 2009.

34. Crump, K. S.; Fundam. Appl. Toxicol. 1984, 4, 854.

35. Setzer Jr, R. W.; Kimmel, C. A.; Pure Appl. Chem. 2003, 75, 2151.

36. Environmental Protection Agency; Choosing a Percentile of Acute Dietary Exposure as a Threshold of Regulatory Concern. Washington, DC, 2000.

37. World Health Organization; Guidelines for Predicting Dietary Intake of Pesticides Residues. Global Environment Monitoring System Food Contamination Monitoring and Assessment Programme (GEM/Foods). Geneva, 1997.

38. Kroes, R. D.; Müllerb, J.; Lambec, M. R. H.; Löwikd, J.; van Klaverene, J.; Kleinerf, R.; Masseyg, S.; Mayerh, I;. Urietai, P.; Vergerj, A.; Food Chem. Toxicol. 2002, 40, 327.

39. Petersen, B. J.; Barraj, L. M.; J. Food Comp. Anal. 1996, 9, 243.

40. http://www.who.int/ipcs/food/exposure_assessment.pdf, acessada em Julho 2009.

41. World Health Organization; Total Diet Studies: a Recipe for Safer Food. Global Environment Monitoring System Food Contamination Monitoring and Assessment programme (GEM/Foods). Geneva, 2005.

42. European Community; Method Validation and Quality Control Procedures for Pesticide Residues Analysis in Food and Feed. Documento $\mathrm{N}^{\circ}$ SANCO/2007/3131

43. INMETRO; Orientação sobre Validação de Métodos de Ensaios Químicos. DOQ-CGCRE-008. Revisão 02, 2007

44. Taverniers, I.; De Loose, M.; Van Bockstaele, E.; TrAC, Trends Anal. Chem. 2004, 23, falta página. 
45. Takatori, S.; Okihashi, M.; Okamoto, Y.; Kitagawa, Y.; Kakimoto, S. Murata, H.; Sumimoto, T.; Tanaka, Y.; J. AOAC Int. 2008, 91, 871.

46. Zhang, J.; Jiang, Y.; Zhou, J.; Fang, D.; Jiang, D.; Liu, G.; Zhang, H.; Xie, J.; Huang, W.; Zhang, J.; Li, H.; Wang, Z.; Pan, L.; Environ. Int. 2008, 34, 799 .

47. Renwick, A. G.; Barlow, S. M.; Hertz-Picciotto, I.; Boobis, A. R.; Dybing, E.; Edler, L.; ???; Food Chem. Toxicol. 2003, 41, 1211.

48. Baert, K.; De Meulenaer, B.; Verdonck, F.; Huybrechts, I.; De Henauw, S.; Vanrolleghem, P. A.; Debevere, J.; Devlieghere, F.; Food Chem. Toxicol. 2007, 45, 1745.

49. Boobis, A. R.; Ossendorp, B. C.; Banasiak, U.; Hamey, P. Y.; Sebestyen, I.; Moretto, A.; Toxicol. Lett. 2007, 180, 137.

50. http://www.who.int/foodsafety/publications/chem/regional_diets/en/, acessada em Julho 2009

51. Petersen, J. B.; Chaisson, C. F.; Douglass, J. S.; Am. J. Clin. Nutr. 1994, $59,240 \mathrm{~S}$.

52. Byrd-Bredbenner, C.; Lagiou, P.; Trichopoulou, A.; J. Hum. Nutr. Diet. 2000, 13, 197.

53. Serra-Majem, L.; MacLean, D.; Ribas, L.; Brule, D.; Sekula, W.; Prattala, R.; Garcia-Closas, R.; Yngve, A.; Lalonde, M.; Petrasovits, A.; J. Epidem Comm. Health 2003, 57, 74.

54. Instituto Brasileiro de Geografia e Estatística (IBGE); Pesquisa de orçamentos familiares 2002 - 2003, Microdados: Rio de Janeiro, 2005.

55. Levy-Costa, R. B.; Sichieri, R.; Pontes, N. S.; Monteiro, C. A.; J. Public Health 2005, 39, 530.

56. Caldas, E. D.; Boon, P. E.; Tressou, J.; Food Chem. Toxicol. 2006, 44 1562.

57. Caldas, E. D.; Souza, L. C. K. R.; Food Addit. Contam, Part A 2004, 21, 1057.

58. Sichieri, R.; Pereira, R. A.; Martins, A.; Vasconcellos, A. B. P. A.; Trichopoulou, A.; BMC Public Health 2008, 8, 89.

59. Sichieri, R.; Everhart, J. E.; Nutr. Res. 1998, 18, 1649.

60. Thomas, K. W.; Sheldon, L. S.; Pellizzari, E. D.; Handy, R.W.; Roberds, J. M.; Berry, M. R.; J. Expo. Anal. Environ. Epidemiol. 1997, 7, 17.

61. Boon, P. E.; van der Voet, H.; van Klaveren, J. D.; Food Addit. Contam., Part A 2003, 20, S36.

62. Velasco-Reynold, C.; Navarro-Alarcon, M.; De La Serrana, H. L.; PerezValero, V.; Lopez-Martinez, M. C.; Food Addit. Contam. Part A 2008, 25,604 .

63. Wilkinson, C. F.; Christoph, G. R.; Julien, E.; Kelley, J. M.; Kronenberg, J.; McCarthy, J.; Reiss, R.; Regul. Toxicol. Pharmacol. 2000, 31, 30.

64. Feron, V. J.; Groten, J. P.; Food Chem Toxicol. 2002, 40, 825.

65. Environmental Protection Agency; Guidelines for the Health Risk Assessment of Chemical Mixtures. EPA/630/R-98/002. Washington, DC. September 1986

66. Safe, S. H.; CRC Crit. Rev. Toxicol. 1990, 21, 51.

67. Safe, S. H.; Environ. Health Perspect. 1998, 106, 1051.

68. van den Berg, M.; Birnbaum, L. S.; Denison, M.; De Vito, M.; Farland, W.; Feeley, M.; Fiedler, H.; Hakansson, H.; Hanberg, A.; Haws, L.; Rose, M.; Safe, S.; Schrenk, D.; Tohyama, C.; Tritscher, A.; Tuomisto, J.; Tysklind, M.; Walker, N.; Peterson, R. E.; Toxicol. Sci. 2006, 93, 223.

69. Mileson, B. E.; Chambers, J. E.; Chen, W. L.; Dettbarn, W.; Ehrich, M.; Eldefrawi, A. T.; Gaylor, D. W.; Hamernik, K.; Hodgson, E.; Karczmar A. G.; Padilla, S.; Pope, C. N.; Richardson, R. J.; Saunders, D. R.; Sheets, L. P.; Sultatos, L. G.; Wallace, K. B.; Toxicol. Sci. 1998, 41, 8.

70. http://www.ewg.org/book/export/html/7877, acessada em Julho 2009.

71. http://www.epa.gov/pesticides/cumulative/pra-op/index.htm, acessada em Julho 2009.

72. Jensen, A. F.; Petersen, A.; Granby, K.; Food Addit. Contam. Part A 2003, 20, 776 .

73. Caldas, E. D.; Boon, P. E.; Tressou, J.; Toxicology 2006, 222, 132.
74. Boon, P. E.; van der Voet, H.; van Raaij, M. T.; van Klaveren, J. D.; Food Chem. Toxicol. 2008, 46, 3090.

75. Groten, J. P.; Heijn, W. H. M.; Stierum, R. H.; Freidig, A. P.; Feron, V. J.; Environ. Toxicol. Pharmacol. 2004, 18,185.

76. Environmental Protection Agency; Guidance for Performing Aggregate Exposure and Risk Assessment. EPA. Office of Pesticide Programs. November 28, 2001

77. Clayton, A. C.; Pellizzari, E. D.; Whitmore, R. W.; Quackenboss, J. J.; Adgate, J.; Sefton, K.; J. Expo. Anal. Environ. Epidemiol. 2003, 13, 100.

78. Petersen, B. J.; Regul. Toxicol. Pharmacol. 2000, 31, 297.

79. http://www.epa.gov/scipoly/sap/meetings/2004/april/charge.htm, acessada em Julho 2009.

80. http://www.efsa.europa.eu/EFSA/efsa_locale-1178620753812_ 1178620820159.htm, acessada em Julho 2009.

81. Finley, B.; Paustenbach, D.; Risk Analysis 1994, 14, 53.

82. Boer, W. J.; Voet, H.; MCRA Release 5, a web-based program for Monte Carlo Risk Assessment. Biometris and RIKILT, Wageningen: The Netherlands, 2006.

83. Goldman, L. R.; Beller, M.; Jackson, R. J.; Arch. Environ. Health 1990, 45,141 .

84. Annual report of the working party on pesticide residues: 1992, Supplement to The Pesticides Register 1993, London, UK: HMSO.

85. Tsai, M. J.; Wu, S. N.; Cheng, H. A.; Wang, S. H.; Chiang, H. T.; J. Toxicol. Clin. Toxicol. 2003, 41, 969.

86. Mendes, C. A.; Mendes, G. E.; Cipullo, J. P.; Burdmann, E. A.; Clin. Toxicol. (Phila) 2005, 43, 117.

87. Hamilton, D. J.; Ambrus, A.; Dieterle, R.; Felsot, A.; Harris, C.; Petersen, B.; Racke, K.; Wong, S.; Gonzalez, R.; Tanaka, K.; Earl, M.; Roberts, G.; Bhula, R.; Pest. Sci.2004, 60, 311.

88. http://www.fao.org/ag/AGP/AGPP/Pesticid/JMPR/download/2003.pdf, acessada em Julho 2009.

89. http://www.who.int/foodsafety/chem/acute_data/en, acessada em Julho 2009.

90. Caldas, E. D.; Jardim, A.; Ambrus A.; Souza, L. C.; Food Addit. Contam, Part A 2006, 23, 148

91. http://www.efsa.europa.eu/EFSA/efsa_locale-1178620753812_ 1178629328713.htm, acessada em Julho 2009.

92. Codex Alimentarius Commission; Report of the Forty-First Session of the Codex Committee on Pesticide Residues. ALINORM 09/32/24. Beijing, 2009

93. Dybing, E.; O’Brien, J.; Renwick, A. G.; Sanner, T.; Toxicol. Lett. 2008, $180,110$.

94. World Health Organization; Evaluation of Certain Food Contaminants. Sixty-Fourth Report of the Joint FAO/WHO Expert Committee on Food Additives. WHO Technical Report Series 930. Geneva, 2006.

95. Caldas, E. D.; Souza, L. C. K. R.; Rev. Saúde Pública 2000, 34, 529

96. Caldas, E. D.; Miranda, M. C. C.; Conceição, M. H. C.; Souza, L. C. K. R.; Food Chem. Tox. 2004, 42, 11877.

97. Azeredo, A.; Torres, J. P. M.; Fonseca, M. F. F.; Britto, J. L.; Bastos, W. R.; Azevedo, C. E. S.; Cavalcanti, G.; Meire, R. O.; Sarcinelli, P. N.; Claudio, L.; Markowitz, S.; Malm, O.; Chemosphere 2008, 73, S246.

98. Caldas, E. D.; Silva, A. C. S.; J. Agric. Food Chem. 2007, 55, 7974.

99. Machinski, M.; Soares, L. M. V.; Food Addit. Contam. 2000, 17, 875.

100. Caldas, E. D.; Machado, L. L.; Toxicology 2004, 42, 599.

101. Rodrigues, M. L. K.; Formoso, M. L. L.; Environ. Geochem. Health 2005, 27, 397.

102. Passos, C. J. S.; Da Silva, D. S.; Lemire, M.; Fillion, M.; Guimarães, J. R. D.; Lucotte, M.; Mergler, D.; J. Exp. Sci. Environ. Epidem. 2008, 18, 76.

103. Popolim, W. D.; Penteado, M. D. E. V. C.; Food Addit. Contam. 2005, $22,1106$.

104. Tfouni, S. A.; Toledo, M. C.; Food Addit. Contam. 2002, 19, 647. 